\title{
Resenha: \\ O ESTADO E A REVOLUÇÃO: O QUE ENSINA O MARXISMO SOBRE O ESTADO E O PAPEL DO PROLETARIADO NA REVOLUÇÃO'
}

\author{
Luciana Vedovato ${ }^{2}$
}

O texto de Lenin não é necessariamente inédito, do ponto de vista da revisão da literatura leninista. O que a tradução de Aristides Lobo apresenta para os leitores é uma precisão em relação aquilo que realmente foi escrito pelo estadista russo. Talvez pelo fato de que o próprio tradutor também fosse um membro do Partido Comunista Brasileiro, assim, a tradução não passa apenas pela literalidade, mas apresenta-se como uma obra rica e detalhada, especialmente no que se refere ao contexto de produção leninista que fica presente durante toda a obra, do entendimento de Lenin sobre as questões surgidas com o proletariado no poder, ocupando o Estado.

Contudo, cabe uma ressalva: não se trata de uma leitura introdutória ao método leninista, assim, para compreender Estado e Revolução é preciso adentrar em outros textos importantes de Lenin, como, por exemplo, Sobre a aliança operária e camponesa - textos de 1899/1921 que apresenta questões sobre como a Rússia organizou a distribuição de terras depois da reforma do sistema feudal e como tal distribuição lançou os camponeses em um estado de penúria cuja alternativa para não morrer era a luta e a aliança com o proletariado já organizado. Outros textos que estabelecem um diálogo com Estado e Revolução são Crítica ao programa de Gotha ${ }^{3}$, Manifesto Comunista, A sagrada família e outros que serão mencionados ao longo da resenha. Também é preciso lembrar que a morte prematura de Lenin fez com que alguns dos seus questionamentos mais profundos sobre como o proletariado ocuparia o Estado e o poder não foram suficientemente esclarecidos, por isso há na obra resenhada mais uma possibilidade de compreensão da questão do Estado do que necessariamente indicativos do modo como os operários deveriam atuar quando, por fim, saíssem gloriosos da revolução.

Nesse sentido o Estado e a revolução é resultado da reflexão de Lenin sobre o modo como os trabalhadores estavam se organizando no poder, mas é também um alerta para o modo como - os marxistas vulgares - expressão do próprio Lenin - juntamente com os populistas ganhavam espaço fazendo alianças com a burguesia, mascarando o interesse que tais líderes tinham pelo poder em detrimento do avanço do Estado do Proletariado.

Assim, Lenin faz uma brilhante análise de como Estado também deveria desaparecer - definhar é o termo - quando, enfim, o comunismo triunfasse.

Para isso ele põe da tomada do poder estatal como uma questão central da luta de classes e para discutir tal proposição, Lenin propõem a reestabelecer a verdadeira doutrina de Marx sobre o Estado (p.24), pois ele avaliava que os burgueses, após a morte de Marx e Engels, apropriaram-se das teorias marxistas deslocando-as do lugar real da história ao

1 LENIN, Vladimir Ilitch. O Estado e a Revolução: o que ensina o marxismo sobre o Estado e o papel do proletariado na Revolução. Trad rev. e anotada Aristides Lobo. São Paulo: Centauro, 2007.

2 Doutoranda do Programa de Pós-Graduação em Letras da Universidade Federal do Rio Grande do Sul.

3 O referido texto trata-se de um comentário de Marx sobre a colisão, no Congresso de Gotha, da união no Partido Socialista da Alemanha, o Partido Operário Socialdemocrata e Bebel. Comentário que explica o motivo de Marx, e também Engels, em distanciarem-se da proposição feita em tal congresso. 
qual elas pertenciam, transformando os dois pensadores em inofensivos e negando toda construção transformadora de Marx e Engels. E para cumprir a tarefa de reestabelecer a doutrina de Marx, Lenin retomas os textos do autor e de Engels para esclarecer o papel do Estado que para Lenin "é o produto e a manifestação do antagonismo inconciliável das classes" (p.25), mas que os reformistas da teoria marxistas estão sempre a dizer não, que o Estado é o responsável pela mediação das classes, quando, de fato, o Estado é a representação máxima da dominação de uma classe por outra, pois sobre a nomenclatura de "conciliador das classes" o que o Estado faz á engendrar práticas para a dominação, pela classe burguesa, pela classe operária.

Para tanto, de acordo com Lenin, o Estado organiza-se de modo a manter-se como instrumento da exploração da classe oprimida. Assim, mantem uma força armada, pela aparelhagem governamental: cargos, estrutura, etc. o que fez com que todo o arranjo do modo de agir do Estado seja em função da manutenção da classe dominante.

O questionamento leninista é bastante veemente. Ao tocar no ponto sufrágio universal que, modernamente, é tomado como o maior dos movimentos democráticos ele faz duras críticas afirmando que os democratas pequeno-burgueses (e aqui ele faz um apontamento para os próprios membros do partido que deixaram-se envolver pela compreensão errônea de que o Estado pode ser o conciliador entre as classes) "partilham e fazem o povo partilhar a falsa concepção de o sufrágio universal, 'no Estado atual' é capaz de manifestar verdadeiramente e impor a vontade da maioria dos trabalhadores" (p.34).

Ora, se fundamentalmente o Estado é ocupado de guardar os valores da burguesia, o sufrágio universal e a democracia também são questionáveis enquanto sistema de representação dos trabalhadores, justamente por conterem em si o princípio que não prevê a igualdade e sim a manutenção de uma das forças, notadamente, a força burguesa.

Continuando a leitura de Marx e Engels, Lenin ${ }^{4}$, aponta para outros desvirtuamentos pelos sociais-democratas modernos - a quem ele chama de oportunistas - e pelos anarquistas. Para Lenin, os oportunistas ao tentar criar a ideia de que o sufrágio universal era um modo de representar a maioria dos trabalhadores, também dissimulava os reais escritos de Engels que afirmava que ao acontecer à igualdade de classes o Estado também não seria mais necessário, também desapareceria. A dura crítica feita por Lenin aos oportunistas encontra razão de ser, pois para o autor, o Estado não pode continuar a existir quando os meios de produção estiverem na mão do proletariado e ao mencionar a passagem de Engels ele explica que quando isso acontece: o proletariado tomar o Estado, eles - os trabalhadores - também se destroem enquanto "classe e abole todas as distinções e antagonismos de classes e, simultaneamente, também o Estado, como Estado." (p.36), mas é preciso fazer notar que tal processo não é a morte do Estado e sim o definhamento, termo cunhado por Engels e que para Lenin é fundamental para compreendermos como tanto os oportunistas como os anarquistas não poderiam reivindicar a teoria de Engels, uma vez que para os primeiros o Estado de fato não definhava, continuava ali a reger, desta vez, o poder do proletariado, para os segundos, a compreensão, segundo Lenin, é de que o Estado deixaria de existir de uma hora para outra.

Porém para não restar dúvidas sobre a compreensão que faz de Engels, Lenin reforça sua leitura apontando para o fato de que suas conclusões são muito mais para desvelar

4 Lenin trata da rivalidade entre os oportunistas e anarquistas durante boa parte do texto, pois, segundo o autor, a leitura de que as críticas de Marx e Engels eram endereçadas apenas aos anarquistas é um equívoco, pois o grande alvo eram os oportunistas que estavam a fazer políticas de troca e aliança dentro do Partido Comunista. 
o falseamento feito pelos oportunistas das teses marxistas do que reforçar a crítica aos anarquistas. Assim ele começa distinguindo a abolição do Estado de seu definhamento e morte. A abolição só pode ser compreendida como a do Estado burguês, ou seja, a tomada da estrutura estatal durante o processo revolucionário e o definhamento e morte viriam depois da revolução, mas conjuntamente, pois primeiro seria preciso que a "força especial de repressão" (p.39) que antes atuava da burguesia sobre o proletariado, passe a ser uma força especial de repressão da burguesia pelo proletariado, ou seja, a posse dos meios de produção, feito isso, o modo de operação da classe burguesa, entrará no processo de definhamento até desaparecer: a morte do Estado.

Ao tratar especificamente do definhamento, Lenin faz um alerta para os que "imprudentemente desvirtuam o marxismo" (p.39) a compreensão do definhamento do Estado, também abarca o conceito de democracia que o Estado burguês toma para si. Desse modo, a revolução abole o Estado burguês e a ditadura do proletariado, isto é, a tomada, pelo proletariado, dos meios de produção, fará definhar a letargia do Estado burguês.

Nesse contexto, a crítica feita por Lenin é que os leitores de Engels equivocam-se acreditando que o texto foi feito para os anarquistas. Para Lenin, Engels repreende duramente os oportunistas por que estes acreditavam ser possível um Estado popular e livre, pois não há democracia que não seja, para alguma parte da população, no regime capitalista, por exemplo, os trabalhadores, uma forma de escravidão:

nós somos partidários da república democrática como sendo a melhor forma de governo para o proletariado sob o regime capitalista, mas andaríamos mal se esquecêssemos de que a escravidão assalariada é o quinhão do povo mesmo na república burguesa mais democrática (p.40).

E para finalizar a discussão sobre esse ponto Lenin revisa um dos pontos de Engels que considera fundamental: a conceituação da revolução violenta e, ironicamente, enuncia que "disso ninguém se lembra" criticando os oportunistas por apagarem tal reflexão para garantir a tomada dos meios de produção. Para Lenin a compreensão de que o definhamento do Estado só é possível pela revolução violenta é deixada de lado pelos sociais-democratas alemãs - e também por aqueles que não querem de fato a revolução - justamente pelo fato de que só ela garantiria a real transformação das estruturas de produção.

O segundo capítulo da obra trata das Experiências de 1848-1851 que trata de dois textos de Marx: A miséria da Filosofia e o Manifesto comunista, ainda no tratamento dado por Engels e Marx para o Estado. Para Lenin o fundamental a ser observado nos dois textos é a referência histórica, uma vez que eles são lançados em 1847, pouco tempo antes da Revolução Francesa e mostram, até certo ponto, que todos os escritos estavam imbuídos do espírito revolucionário.

Lenin retoma o conceito de definhamento do Estado para tocar em outro ponto importante da teoria marxista sobre o assunto: a ditadura do proletariado. Para o autor os reformistas da teoria de Marx e Engels esqueceram esse conceito fundamental e acreditavam em tuas teses falsas: a possibilidade do desenvolvimento pacífico da democracia e a necessidade de um Estado para ajudar o proletariado. Lenin refuta as duas teses apontando que não há como a burguesia deixar o poder que não seja pela revolução violenta e que o proletariado só precisa do Estado em definhamento até subjugar as classes exploradoras, feito isso cessa a necessidade do Estado, quando o proletariado reorganiza os meios de produção e atinge a supremacia política "sem partilha e apoiado diretamente na força das massas armadas" (p.49) torna-se inevitável a derrubada da burguesia. 
Lenin ao fazer a leitura de Marx e Engels apontava para o fato de que os reformistas da teoria marxistas logo abandonavam os pontos importantes para não ocupar-se da real transformação do Estado. Ao mencionar Kausty ${ }^{5}$ Lenin pontua que ao negar a destruição do Estado e, da mesma maneira que a burguesia apropriar-se do Estado ocupando postos no aparelho burocrático e militar, não há nenhuma transformação. Há uma tentativa de reforma, mas a reforma como bem pontua Lenin que aqueles que apenas reconhecem a luta de classe não é ainda marxista, "só é marxista aquele que estende o reconhecimento da luta de classes ao reconhecimento da ditatura do proletariado" (p.59).

No capítulo III, Lenin faz uma leitura de Marx e a experiência deste com a Comuna de Paris (1871). Para Marx, segundo a leitura de Lenin, a revolução em 1871 poderia ser um risco. Mas uma vez ocorrida, diferente dos oportunistas como Plekhânov, Marx não criticou e sim tratou de fornecer análises e observações para a construção de uma nova realidade. Os pontos levantados por Lênin são justamente referentes ao modo como a organização do Estado ocorreu logo depois da revolução de 1871: não bastava apenas apoderar-se do Estado, era preciso quebrá-lo, destruí-lo e em termos marxistas "não passar para outras mãos a máquina burocrática e militar - como se tem feito até aqui - mas quebra-la" (p.63). E para isso não há na perspectiva de Marx e também na de Lenin, como fazer o movimento revolucionário sem estabelecer uma aliança com operários e camponeses: "a revolução capaz de arrastar a maioria do movimento só poderia ser popular com a condição de englobar o proletariado e os camponeses (...) sem essa aliança, não há democracia sólida nem transformação possível" (p.65).

Na avaliação de Marx - segundo a leitura de Lenin - a Comuna cometeu alguns erros que custaram à revolução: o contentamento com a supressão do exército permanente, a elegibilidade e amovibilidade de todos os funcionários, mas para Lenin, apenas essas medidas, mesmo que fundamentais, não foram suficientes para que a igualdade chegasse para todos.

Outro ponto mencionado por Lenin diz respeito ao fato que a Comuna manteve o parlamento e delegou aos anarquistas toda a crítica ao parlamentarismo. Para o autor o modo de sair do parlamentarismo

Não é, certamente, anular as instituições representativas e a elegibilidade, mas sim transformar esses moinhos de palavras que são as assembleias representativas em assembleias capazes de trabalhar verdadeiramente. A Comuna devia ser uma assembleia, não parlamentar, mas trabalhadora, ao mesmo tempo legislativa e executiva (LENIN, 2005, p.73).

E a análise leninista também se alonga para a questão da existência política do funcionamento do Estado, uma vez que para ele, todo o aparato de cargos do Estado deveria ser acessível à população, não deveriam os cargos, apresentarem uma conotação superior e, por isso, serem remunerados de forma exorbitante. Se todos pudessem conhecer os ofícios do trabalho no Estado, todos poderiam receber o "salário de um operário" (p.77).

Para tanto, Lenin aponta, nas leituras de Marx, que para que o Estado burguês seja destruído é preciso que haja a centralização das organizações das tarefas nas mãos do proletariado. É uma dura crítica ao federalismo de Proudhon e Bakuin que pensavam em um Estado federalizado ${ }^{6}$. Não há outra forma de lutar contra o poder burguês e em favor

5 Líder do partido social democrata alemão.

6 Como exemplo de federalismo podemos tomar a organização do Estado Brasileiro que é constituído de Estados que têm suas regulamentações especiais garantindo o direito de propriedade, à posse, a relação com outros estados, mas todos seguem uma lei maior que garante a própria existência dos estados. A federação é responsável, desse modo, pela regulamentação geral, pelo alinhamento econômico e político dos estados. 
da destruição do Estado que não seja centralizando as tarefas na organização proletária, por isso, era preciso sim acabar com a centralização, mas aquela proposta pela burguesia enquanto operado do Estado, feito que a Comuna - se não conseguiu totalmente, ao menos mostrou que era possível à organização para a revolução proletária.

No capítulo IV, Lenin trata o que chamou de Esclarecimentos complementares de Engels, ainda considerando o tratamento dado por Engels e Marx para a questão do Estado, o autor aponta alguns problemas a serem resolvidos, entre eles, a habitação e, de um modo geral, os bens pertencentes à burguesia. A compreensão de Engels é que o Estado burguês já executa a supressão de bens, terras, imóveis, etc., do proletariado e isso, no período em que o Estado estivesse tomado pelos trabalhadores, precisaria funcionar de forma inversa, ou seja, redistribuir os bens para que todos tivessem terras, imóveis, etc. E enquanto durar o definhamento do Estado e a divisão de classe nesse processo, os aluguéis ainda seriam cobrados e nesse ponto ele também entra em outra questão que é a polêmica com os anarquistas.

$\mathrm{Na}$ leitura de Engels e Marx feita por Lenin é bastante clara: qualquer organização que fale do Estado como aliado no processo revolucionário (como os sociais-democratas) ou que queira a derrubada do Estado de um dia para o outro (como os anarquistas) não reflete bem os princípios revolucionários, pois não há como acreditar que o Estado, em sua forma atual, possa servir aos interesses dos trabalhadores e nem sequer pode-se supor uma revolução sem autoridade, sem organização, sem armas, como pretende os anarquistas.

E Lenin volta a tocar na questão quando fala da crítica de Marx e Engels ao programa de Gotha e também ao projeto do programa de Erfurt. Nesse capítulo, além das duras críticas ao programa reformistas dos sociais-democratas, há uma discussão fundamental para a compreensão da sociedade comunista que é Eliminação da democracia, segundo Engels (p.116), tópico que já havia sido iniciado com a discussão do sufrágio universal, para Lenin definhamento do Estado, levaria ao definhamento da democracia, pois em uma sociedade comunista não haveria a submissão da minoria à maioria, pois de acordo com o autor o objetivo final "é a supressão do Estado", isto é, de toda violência, organizada, sistemática, de toda coação sobre os homens em geral (p.118), em uma sociedade sem classes, também não há necessidade de submissão de um homem a outro, pois "os homens, com efeito, se habituarão a observar as condições elementares da vida social sem constrangimento nem subordinação" (. 118).

A reflexão leninista é para a liberdade. E homens livres sabem quando é necessária a autoridade, sabem também respeitar as normas e, especialmente, sabem manter o princípio da disciplina para que as conquistas não sejam perdidas. Há um ponto importante também na discussão de Lenin que é o fato da instrução do proletariado de forma clara, fazendo com que todos participem dos movimentos da revolução, para que não haja falsas impressões sobre o que se deve fazer e como se deve agir.

No capítulo V Lenin discute as questões econômicas do definhamento do Estado a partir da crítica do programa de Gotha ${ }^{7}$. Para Marx, a questão do Estado e seu definhamento era uma reflexão da evolução do processo revolucionário:

7 A carta em questão é uma revisão e uma crítica - item por item - que Marx faz ao programa de Gotha. Marx fica bastante contrariado com a leitura do programa e acredita que o lançamento das normativas foi feito de modo antecipado e sem discussões mais aprofundadas o que causou dúvidas e incertezas. A mais dura crítica - também retomada por Lenin - diz respeito ao enunciado Estado Livre: Estado livre, o que é isso? Tomar o Estado 'livre' não é de modo algum o objetivo de trabalhadores já libertos da estreita consciência do súdito (MARX, 2012, p.42). 
Toda a teoria de Marx é a teoria da evolução, na sua forma mais lógica, mais completa, mais refletida e mais substancial, aplicada ao capitalismo contemporâneo. Marx devia, naturalmente, aplicar essa teoria à falência iminente do capitalismo e ao desenvolvimento futuro do comunismo futuro (LENIN, 2007, p.120).

O segundo ponto do capítulo diz respeito justamente ao modo como Marx concebia a transição do capitalismo ao comunismo e a ditadura do proletariado é mais uma vez retomada por Lenin. Para ele, não há meios de conceber uma passagem do capitalismo para o comunismo sem que primeiro os proletários se organizem para tomar o Estado, utilizarse dele para fazer quebrar a resistência dos capitalistas exploradores; reprimir a atividade dos exploradores capitalistas para que não haja organização contra os trabalhadores e por fim a definição de um outro conceito de democracia a partir da ditadura do proletariado:

A democracia, para a imensa maioria do povo, é repressão pela força das atividades dos exploradores, dos opressores do povo, por outras palavras, a sua exclusão da democracia - eis a transformação que sofre a democracia no período da transição do capitalismo ao comunismo. (p.126)

A passagem é bastante esclarecedora, pois como se pode perceber, não outro meio de haver democracia no comunismo que não seja pela ditadura do proletariado, pela organização política dos operários em classe dominante e, a partir de então, a supressão do agir da classe burguesa até a compreensão de que para uma sociedade sem classes não há maioria ou minoria, que não pode haver uma democracia de uma maioria sobre a minoria, pois esses dois polos deixarão de existir na sociedade comunista. Para Lenin "a passagem da sociedade capitalista para a sociedade comunista é impossível sem um período de transição política em que o Estado não pode ser outra coisa senão a ditadura revolucionária do proletariado". (p.123)

Outro ponto que Lenin volta a tocar ao falar da transição do capitalismo ao comunismo é o conceito de democracia. Para ele a democracia proposta pelo capitalismo não é uma democracia, pois sempre é a vontade de uma minoria sobre uma maioria esmagada pelas condições de produção que não permite que a grande massa assalariada tenha tempo para refletir questões políticas e sociais ${ }^{8}$. Nesse sentido, há um falso efeito de que existe democracia, quando na verdade, não há acesso à participação política, nem mesmo modos de formar a consciência para a formação política, uma vez que todas as formas de dominação simbólica ou são ocupadas pelo Estado ou pela classe dominante (escolas, teatros, etc.). $\mathrm{O}$ falso efeito de democracia é garantido pelos dizeres de Marx, retomados por Lenin (p.125) "os oprimidos são autorizados, uma vez cada três ou seis anos, a decidir qual, entre os membros da classe dominante, será o que, no parlamento, os representará e os esmagará!’.

Para Lenin apenas a ditadura do proletariado faria com tal processo cessasse. Mas ele apresenta a situação com clareza histórica: não se trata de alagar a democracia para atender os pobres e sim fazer da vontade do povo, dos pobres, dos trabalhadores, a democracia e aqui o Estado mais uma vez tem papel fundamental: não irá servir de instrumento para mediação das classes, mas tomado pelo proletariado servirá para triunfar sobre o adversário,

8 Para ilustrar tal situação, basta que peguemos os trabalhadores de supermercados: a jornada de trabalho é de 10, 12 horas por dia, quase tudo que é preciso para a existência está ali dentro (roupas, comida, etc.), por causa dos turnos de trabalho dificilmente os trabalhadores se reúnem, não há lugar para a coletividade. Assim, eles não se envolvem socialmente, não possuem uma vida fora do trabalho e sequer refletem sobre as questões políticas. São escravos também, mas pensam viver em uma democracia, porque votam. 
restringir-lhe os direitos, a liberdade e quando, de fato, a igualdade e a liberdade existirem, o Estado também deixará de ser necessário.

E ainda ao tratar da sociedade comunista, Lenin faz uma leitura da Crítica do Programa de Gotha (MARX, 2012), para explicar que as conjecturas lassalianas ${ }^{9}$ eram frágeis, justamente por acreditar que seria possível abandonar todo o modelo capitalista existente e começar do zero e nessa primeira fase do comunismo - ou comunismo inferior - o Estado seria utilizado justamente para subverter a ordem do poder estabelecido. Essa primeira fase, nominada de socialismo por Marx, prevê justamente o fim da exploração do homem pelo homem, "pois ninguém mais poderá dispor, a título de propriedade privada, dos meios de produção, das fábricas, das máquinas, da terra “(p.131).

Mas participação igualitária nos meios de produção não significa ainda igualdade, pois ainda prevê a divisão fruto do trabalho. A perspectiva lassaliana é completamente derrubada por Marx (2012)

No interior da sociedade cooperativa, fundada na propriedade comum dos meios de produção, os produtores não trocam seus produtos, do mesmo modo, o trabalho transformado em produtos não parece aqui como valor desses produtos, como uma qualidade material que eles possuem, pois agora, em oposição à sociedade capitalista, os trabalhos individuais existem não mais como um desvio, mas imediatamente como parte integrante do trabalho total. A expressão fruto do trabalho, que hoje é condenável por sua ambiguidade, perde todo o sentido (p.29) ${ }^{10}$.

É o direito burguês que Marx questiona ao perguntar se o fruto do trabalho pertence integralmente a toda à sociedade. A questão é até mesmo os que não trabalham receberam o fruto integral do trabalho? Respondendo a tal questão, Marx (2012) reflete a questão dentro do programa comunista, explicando, assim como Lenin o fez que para existir a ditatura do proletariado também será preciso organizar uma nova ordem econômica a partir da divisão dos recursos oriundos do trabalho coletivo ${ }^{11} \mathrm{e}$ a partir de tal condição que o comunismo ultrapassa o socialismo e apaga, gradativamente, o capitalismo.

Por fim, no VI e último capítulo, Lenin trata do que chamou de aviltamento do marxista pelos oportunistas. Para o autor autores como Plekhânov, Kautsky e este último é para a leitura leninista tão oportunista quanto Bernstein, pois também deixou de tratar a questão do Estado da forma como Marx havia refletido, desfigurando assim o marxismo em prol da manutenção do poder sem a destruição da máquina do Estado (p.148). Essa concessão, do ponto de vista leninista, é só o princípio de uma série de distorções que Kaustky fará do programa marxista, uma vez que falara ainda do programa vitorioso do proletariado, por meio da democracia (o conceito de democracia burguesa), ele acreditava ainda que a luta em si já traria as mudanças necessárias, não sendo necessário intervir nas questões do Estado.

Ainda nesse capítulo Lenin abordará outro autor Pannekoek que envolvido com a polêmica de Kautsky esforça-se em apresentar os conceitos do marxismo a partir do "centrismo" conforme pontou a leitura leninista. Assim como Kaustky, mas por caminhos

9 Ver mais informações em https://www.marxists.org/portugues/dicionario/verbetes/1/lassalle.htm .

$10 \mathrm{O}$ enunciado "fruto do trabalho integral" é o primeiro item do programa de Gotha: 1) O trabalho é a fonte de toda riqueza e toda cultura, e como o trabalho útil só é possível na sociedade e por meio da sociedade, o fruto do trabalho [Arbeistsertrag] pertence inteiramente, com igual direito, a todos os membros da sociedade. (MARX, 2012, p.23). Marx desconstrói o argumento do programa de Gotha, inclusive, linguisticamente questionando os elementos conectivos da frase.

11 Ver obra citada acima, p.28. 


\section{Conexão Letras}

diferentes, Pannekoek deixou de lado os ensinamentos marxistas para de alguma forma apresentar uma leitura do que seria revolução, a luta do proletariado, contudo também renunciou em discutir o Estado. Assim, como os demais, o interesse era muito mais construir um projeto de governo, já pensando em como ocupar o Estado depois de vencida à classe dominante, do que necessariamente, por fim na luta de classe levando junto o Estado. O oportunismo para Lenin é justamente esse desvirtuamento da teoria marxista para manter o poder, manter a estrutura burocrática do Estado, os cargos, etc., com a falsa desculpa de que tal manobra servirá para o povo. Não será e Marx - em todas as passagens mencionadas por Lenin - elucida a questão: não haverá igualdade enquanto houver classe e o Estado só deverá existir enquanto a ditatura do proletariado organiza uma nova realidade social em que todos trabalharão, todos terão papel importante e a democracia não seja a representatividade vazia, onde trabalho material e intelectual seja fundido e os seres de maneira igualitária existam.

A leitura de $O$ Estado e a Revolução é fundamental para compreendermos como o Estado organiza as instituições e estas organizam as formações ideológicas que atingiram os sujeitos em seus discursos e filiações. Para entender as relações de contradição e aliança de forças antagônicas e, especialmente, nortear-se por uma leitura densa de como o pensamento marxista não pode ser deixado de lado na compreensão das questões do Estado e suas relações com a classe dominante e com o proletariado.

\section{Referências}

ENGELS, F. MARX, K. A sagrada família: ou a crítica da Crítica: contra Bruno Bauer e consortes Trad. Marcelo Backes São Paulo: Boitempo, 2003.

O Manifesto Comunista. Trad. Álvaro Pina. São Paulo: Boitempo,1998.

LENIN, V. I. O Estado e a Revolução: o que ensina o marxismo sobre o Estado e o papel do proletariado na Revolução. Trad. Aristides Lobo. São Paulo: Centauro, 2007.

. Sobre a aliança operária e camponesa: textos 1899/1921. S/L: Editora 17 de Outubro, 1975.

. O que fazer. São Paulo: Hucitec, 1988.

MARX, K. Crítica do Programa de Gotha. Trad. Rubens Enderle. São Paulo: Boitempo, 2012.

. O Dezoito Brumário de Louis Bonaparte. 4. ed, São Paulo: Centauro, 2006. Trad. Silvio Donizete Chagas 